\title{
Supplementation of Mangosteen (Garcinia mangostana) Pericarp Filtrate in Tris-egg yolk-based Diluent on Buck Sperm Membrane Integrity
}

\author{
$\underline{\text { Nurul Isnaini }}^{\text {a)*}}$, Sri Wahjuningsih, Nuryadi and Eko Nugroho \\ Faculty of Animal Husbandry, University of Brawijaya, Malan

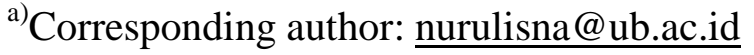

\begin{abstract}
This study was conducted to evaluate supplementation of Mangosteen (Garcinia mangostana) pericarp filtrate in a tris-egg yolk-based diluent on buck sperm membrane integrity after cooling. Semen was collected from 5 bucks by artificial vagina method. Fresh semen evaluated for colour, $\mathrm{pH}$, volume, concentration, mass motility, motility, viability, sperm abnormality and sperm membrane integrity. Semen was diluted with tris-egg yolk-based extender supplemented with different levels Mangosteen (Garcinia mangostana) pericarp filtrate (0, 10, 20 and $30 \%$ ) $\mathrm{v} / \mathrm{v}$ with the ratio of 1 semen : 9 diluter. Semen used mass motility of $2+$ and motility of $70 \%$. Immediately after dilution semen was stored for $4{ }^{\circ} \mathrm{C}$ and sperm membrane integrity percentage were observed at $0,24,48 \mathrm{~h}$ and $72 \mathrm{~h}$. The obtained data were analyze with Analysis of Variant (ANOVA) and Least Significant Difference was determined. The experiment was designed using completely random design ( 4 treatments and 10 replications). The results showed that the level of mangosteen pericarp filtrate had very significant effect $(\mathrm{P}<0,01)$ on sperm membrane integrity percentage in $0,24,48$ and $72 \mathrm{~h}$ of cooling. It concluded that the best mangsteen pericarp filtrate level for resulting optimal sperm membrane integrity was $10 \%$.
\end{abstract}

Key words: AI, antioxidant, dilution, mangosteen, semen quality

\section{INTRODUCTION}

Artificial Insemination (AI) is one of the reproductive technologies that is very efficient and effective in supporting programs of genetic improvement of livestock. To support the efficiency of the AI, sufficient quantity and good quality of semen need to be available when required. In reality, not all male animals have a good genetic quality, so to obtain prospective candidate bucks as the source of germplasm must be strictly selected for excellence and females must come from parents of good quality. Thus, the superiority of males are expected to be passed on to offspring produced in significant amounts is limited, unless it is possible to serve the AI in females with large numbers, using semen be diluted with a good quality extender for the life of sperm (Isnaini, 2006). Attempts to dilute the buck semen and sustain the quality of sperm after cooling to crossbreed etawah bucks in rural areas is difficult as laboratory facilities for freezing buck semen are not available. Under conditions of simple equipment ownership in rural areas, AI breeders can work independently so that good-quality males that there can be more efficiently utilized. 
The extender should be able to increase semen volume and maintain sperm fertilization. For this it is necessary for the extender to maintain the isotonic osmotic pressure with semen and can maintain isotonic pressure during storage, provide balance mineral elements needed for life of sperm, provide nutrients for aerobic and anaerobic metabolism, provide a buffer to prevent $\mathrm{pH}$ changes due to the formation of lactic acid from the metabolism of sperm, prevent oxidative stress due to prolonged storage, prevent the growth of bacteria and increase the volume of semen so that more females can be inseminated with a single ejaculate (Susilawati, 2011).

Tris-egg yolk is the basic extender of simple semen buck diluter and it is made for the purpose of maintaining the $\mathrm{pH}$ and osmotic pressure and also to maintain essential inorganic ion concentrations. Mangosteen pericarpis the biggest part of the mangosteen fruit (Garcinia mangostana L.) were categorized as waste. Study of the phytochemical indicate that the antioxidant compounds in the extract of mangosteen pericarp, especially xanthones, anthocyanins and groups of phenolic compounds other has the functional properties and health benefits such as antidiabetic, anticancer, anti-inflammatory, boost immunity, antibacterial, antifungal, anti-plasmodial, etc. (Permana, et al., 2012). Other researchers also say that the peel of the mangosteen (Garcinia mangostana $L$.) xhantone contain compounds that have pharmacological activity and antioxidant (Ho, et al., 2002).

Mangosteen pericarphas a total phenolic content and antioxidant activity is high (Dungir et al., 2012). Phenolic compounds have been reported to react with reactive oxygen species, this is due to one or two hydroxy groups on the aromatic ring that can act as a donor hydrogen and has the ability to capture free radicals (Ramle et al., 2008). Windono et al. (2001) suggest that antioxidants can act as a contributor to the radical hydrogen or can act as an acceptor of free radicals that can delay the initiation stage free radical formation, other than that antioxidants also serves to stabilize free radicals with a complete lack of electrons from free radicals that inhibit the chain reaction.

Until now still not known how the mangosteen pericarp filtrate can maintain the quality of goat spermatozoa during cooling. This study was conducted to evaluate fortification Mangosteen (Garcinia mangostana) pericarp filtrate in a tris-egg yolk-based diluent on sperm motility of chilled buck semen.

This study was conducted to evaluate supplementation of Mangosteen (Garcinia mangostana) pericarp filtrate in a tris-egg yolk-based diluent on buck sperm membrane integrity after cooling.

\section{METHODS}

\section{Preparation of Mangosteen (Garcinia mangostana) pericarp filtrate}

Mangosteen (Garcinia mangostana) pericarp filtrate prepared by blending: 5 gripe Mangosteen (Garcinia mangostana) pericarp $+500 \mathrm{ml}$ aquadest, and the mixture was then filtered using filter paper $(0.48 \mu \mathrm{m})$ and deposited to form the supernatant and precipitate. Supernatant (Mangosteen pericarp filtrate ) was stored in a freezer temperature of $-20^{\circ} \mathrm{C}$.

\section{Semen Collection and fresh semen evaluation}

Semen was collected from 5 bucks of cross breed etawah goat. Semen was collected 1 times a week by artificial vagina method. To minimize stress and maximize the quality of semen, semen collection was always done by the same person, at the same time, and under the same conditions. After collection, the semen was evaluated for volume, $\mathrm{pH}$ (with lacmus paper), concentration (calculated by using a hemocytometer), sperm mass motility (light microscope 100x magnification), motility (light microscope 400x magnification), viability and morphology (in 
nigrosin-eosin smears under a light microscope, 400x magnification). Only semen with mass motility of $2+-3+$ and motility of sperm more than $70 \%$ was used for research material.

\section{Semen Dilution, Storage and Evaluation}

The selected semen was diluted with tris-egg yolk-based extender containing 0, 10, 20 and 30\% v/v of Mangosteen pericarp filtrate. Semen was diluted in ratio of 1 semen: 9 diluter $(0.1 \mathrm{ml}$ semen: $0,9 \mathrm{ml}$ of diluter). Diluted semen was placed into $1.5 \mathrm{ml}$ closed eppendorf tubes. To determine the effect of level of Mangosteen pericarp filtrate on the motility of chilled buck sperm, semen was evaluated after cooling $\left(3-5^{\circ} \mathrm{C}\right)$ at $0,24,48$ and $72 \mathrm{~h}$.

\section{Data analysis}

The obtained data were analyzed by Analysis of Variance (ANOVA) and continued by Least Significant Difference calculated if there was significant or very significat different between groups. The experiment was designed using a completely random design ( 4 treatments and 10 replications).

\section{RESULTS}

\section{Characteristics of fresh semen}

The collected semen was examined the characteristics before treated with tris-egg yolk-based extender combined with Mangosteen pericarp filtrate (Table 1).

Table 1. Characteristics of fresh semen $(n=10)$

\begin{tabular}{|l|c|}
\hline \multicolumn{1}{|c|}{ Parameter } & Value \\
\hline Color & Creamy \\
\hline $\mathrm{pH}$ & $7.00 \pm 0.0$ \\
\hline Volume (ml/head) & $1.13 \pm 0.38$ \\
\hline Concentration (10 $/ \mathrm{ml})$ & $394.00 \pm 44.19$ \\
\hline Mass motility (\%) & $3+$ \\
\hline Individual motility (\%) & $77.00 \pm 4.83$ \\
\hline Viability (\%) & $81.69 \pm 5.18$ \\
\hline Abnormal sperm (\%) & $7.63 \pm 0.70$ \\
\hline Membrane integrity (\%) & $72.51 \pm 6.67$ \\
\hline
\end{tabular}

\section{Sperm Membrane Integrity}

Percentage of sperm membrane integrity of bucks semen after cooling diluted with tris-egg yolk-based extender containing different levels of MPF at different times of cooling are shown in Table 2. 
Table 2. Percentage of sperm membrane integrity following treatment with different MPF levels after cooling

\begin{tabular}{|l|c|c|c|c|}
\hline \multirow{2}{*}{$\begin{array}{c}\text { Time of } \\
\text { cooling (h) }\end{array}$} & \multicolumn{4}{|c|}{ MPF levels (\%) } \\
\cline { 2 - 5 } & 0 & 10 & 20 & 30 \\
\hline $\mathbf{0} * *$ & $60.50 \pm 4.67^{\mathrm{b}}$ & $62.00 \pm 3.22^{\mathrm{b}}$ & $54.40 \pm 7.02^{\mathrm{a}}$ & $52.70 \pm 1.70^{\mathrm{a}}$ \\
\hline $\mathbf{2 4} * *$ & $47.00 \pm 7.49^{\mathrm{bc}}$ & $51.90 \pm 4.94^{\mathrm{c}}$ & $45.90 \pm 5.75^{\mathrm{b}}$ & $36.70 \pm 78.73^{\mathrm{a}}$ \\
\hline $\mathbf{4 8}^{* *}$ & $31.00 \pm 8.75^{\mathrm{bc}}$ & $36.80 \pm 8.48^{\mathrm{c}}$ & $24.70 \pm 7.72^{\mathrm{ab}}$ & $20.90 \pm 67.72^{\mathrm{a}}$ \\
\hline $\mathbf{7 2} * *$ & $12.00 \pm 6.69^{\mathrm{b}}$ & $14.00 \pm 6.99^{\mathrm{c}}$ & $10.50 \pm 7.91^{\mathrm{ab}}$ & $8.00 \pm 3.50^{\mathrm{a}}$ \\
\hline
\end{tabular}

$\mathrm{a}, \mathrm{b}$ highly significant different $(\mathrm{P}<0.01)$

\section{DISCUSSION}

The results showed that the level of MPF had very significant effect $(\mathrm{P}<0.01)$ on sperm membrane integrity percentage in $0,24,48$ and $72 \mathrm{~h}$ of cooling. Levels $10 \%$ MPF produced the highest percentage of sperm membrane integrity, followed by the level of $0 \%, 20 \%$, and $30 \%$ MPF. Sperm membrane integrity decreased gradually as the duration of cooling. The longer the cooling the lower the sperm membrane integrity.

Mangosteen pericarp filtrate level of $10 \%$ is optimal for sperm membrane integrity after cooling. The level of $0 \%$ of Mangosteen peel filtrate influenced suboptimal effect on the sperm membrane integrity, might be due to the low concentration for maintaining function in the diluter during cooling. A contrast different was observed in samples with addition of 20 and 30\% MPF. Level MPF $20 \%$ and $30 \%$ in tris-egg yolk extender was unable to maintain the quality of sperm at the same time, because the concentration was added to the extender is too high, and the extender have higher concentrations or hypertonic. The higher the concentration the higher osmolarity of the extender. Conditions hypertonic extender will cause lethal to sperm. The improper influence of osmolarity as a result of the addition of extender concentrations are not exactly expected to result in the loss of natural antioxidants and other essential components in the seminal plasma needed to maintain membrane integrity and sperm function as membrane components has changed the structure so that optimal function decline (Maxwell and Johnson, 1999).

Decrease in the percentage of sperm membrane integrity after cooling is due to fewer sperm that have intact sperm membrane. MPF supplementation in basic diluent Tris able to maintain the integrity of the sperm membrane during cooling, because MPF contains xhantone which is an antioxidant plant in a high number (polyphenolic compounds) that can counteract the free radicals caused by cooling. Secondary metabolites materials required antioxidants to protect sperm from damage due to the accumulation of $\mathrm{CO}_{2}$, lactic acid and free radicals (Kaeoket et.al., 2011). Formation of free radicals as mediators of biochemical reactions required normally, but if it can lead to excessive regeneration broad reaction against macromolecules and cell damage (Kothari et. al., 2010). In general, mature sperm capable of producing reactive oxygen species (ROS), which is a major contributor to oxidative stress is responsible for the destruction of the function of sperm. Accumulation of free radicals cause oxidative stress. Oxidative stress will cause the sperm membrane lipid peroxidation and the induction of oxidative DNA damage (Aitken et. al ., 2012) . Sperm membrane lipid peroxidation would lead to destabilization, which results in increased permeability of the membrane to the surrounding ions, including calcium ions. Active oxygen and free radicals, such as superoxide anion $\left(\mathrm{O}_{{ }_{2}}{ }^{-}\right)$, hydrogen peroxide $\left(\mathrm{H}_{2} \mathrm{O}_{2}\right)$ and free radical $(\bullet \mathrm{OH})$, 
formed constantly in the metabolic activity of spermatozoa. Therefore much attention has been focused on inhibiting lipid peroxidation, or protect cell damage from free radicals (Hui - Yin and Gow - Chin, 2006).R.J

To protect sperm from free radical damage during cooling, it is necessary to add antioxidants in the extender. Antioxidants work by inhibiting or delaying oxidative damage of proteins, nucleic acids and lipids, which are caused by free radicals during cooling. Antioxidants can neutralize or prevent cell damage caused by free radicals or break the chain by inhibiting oxidative reactions during the formation of radicals, producing molecules from oxidation activity by oxidizing molecules themselves, thereby reducing oxidative stress (Bansal and Bilaspuri, 2011).

Spermatozoa that have undergone cold stress can have destabilized membranes. Membrane destabilization will increase membrane permeability to calcium ions that would result in the increase in cytosolic calcium ion followed by increasing calcium ions in mitochondria. The high concentration of calcium ions in the mitochondrial ATP synthesis will decrease in mitochondrial energy reserve that can be used for sperm motility (Isnaini, 2006). The addition of Mangosteen pericarp filtrate in semen extender serves to stabilize the sperm membrane so that the sperm membrane destabilization can be suppressed.

\section{CONCLUSION}

Based on the study, it was concluded that the addition 10\% MPF in tris-based medium resulting optimal sperm membrane integrity of Boer goat semen after cooling

\section{References}

R.J. Aitken, K.T. Jonesand S.A. Robertso,Androl 33(6):1096-1106 (2012).

A.K. Bansaland G.S. Bilaspur,. Veterinary Medicine International:1-7 (2011)

S.G. Dungir, D.G.KatjaadanS.K Vanda, MIPA Unsrat, Manado. 1(1):11-15 (2012)

C.K. Ho, Huang and Chen,Planta Med., 68: 975-979(2002).

C. Hui-Yin, andY. Gow-Chin,Foodchem. 02(047): 686-694 (2008).

N. Isnaini, N. "Peranan Trehalosa Dalam Pendinginan dan Pembekuan Semen". Disertasi Pascasarjana Universitas Brawijaya, 2006.

K. Kaeoket, P. Chanapai, Junchiyaphoom and P. Chanapiwat,Thai Vet Med, 41(3): 283 - 288 (2011).

S. Kothari, A. Thomson, .A. Agarwal andS.S. du Plessis. Review article: Indian Journal of Experimental Biology 48: 425-435 (2010).

W.M. Maxwelland L.A. Johnson .Theriogenology. 52(8):1353-62 (1999).

A.W. Permana, S.M.Widayanti, S.PratawatidanD.A. Setyabudi,Pascapanen 9 (2): 88-95(2012).

S.F.M. Ramle,.F. Kawamura,O.Sulaiman, R. Hashim, Proceeding International Conference of Environmental Research and Technology. Pp: 472-475 (2008).

T. Windono, S.Soediman, U.Yudawati, E.Ermawati, Srielita, T.I. Erowati, Artocarpus 1: 34 43(2001).

T. Susilawati. Spermatologi (Universitas Brawijaya Press, Malang, 2011), pp 30-35 